\title{
Soft tissue reconstruction after lower extremity limb-sparing pediatric sarcoma resection
}

\author{
Kevin Shultz ${ }^{1}$, Nicholas Webster ${ }^{1}$, Miguel A. Soto-Miranda ${ }^{2}$, Anas Eid ${ }^{3}$, Jon P. Ver Halen ${ }^{1}$ \\ ${ }^{1}$ Division of Plastic Surgery, Scott and White Memorial Hospital, Temple, TX 76508, USA. \\ ${ }^{2}$ Private Practice, Mexico City 05109, Mexico. \\ ${ }^{3}$ Division of Plastic and Reconstructive Surgery, Baptist Cancer Center, Memphis, TN 38139, USA.
}

Correspondence to: Prof. Jon P. Ver Halen, Baylor Scott \& White Health, 2401 South 31st St, Temple, TX 76508, USA. E-mail: jpverhalen@gmail.com

How to cite this article: Shultz K, Webster N, Soto-Miranda MA, Eid A, Ver Halen JP. Soft tissue reconstruction after lower extremity limb-sparing pediatric sarcoma resection. Plast Aesthet Res 2016;3:311-9.

\begin{tabular}{|c|c|c|c|}
\hline \multirow{2}{*}{$\begin{array}{l}\text { Article h } \\
\text { Received: } \\
\text { Accepted } \\
\text { Published }\end{array}$} & \multirow{3}{*}{\multicolumn{2}{|c|}{$\begin{array}{c}\text { This article has been withdrawn by the authors. The same patient data are being used for a } \\
\text { case series review by other senior researchers, not listed in this article. The authors state that } \\
\text { this does not affect the overall conclusions of the study. }\end{array}$}} & \multirow{3}{*}{$\begin{array}{l}\text { children. } \\
\text { e defects. } \\
\text { sarcoma } \\
\text { f patients } \\
12 \text { years. } \\
\text { e } 2.9-23.3 \\
\text { included }\end{array}$} \\
\hline & & & \\
\hline \multirow{2}{*}{$\begin{array}{l}\text { Key worc } \\
\text { Pediatric, } \\
\text { bone sarco } \\
\text { limb-salva } \\
\text { reconstruct }\end{array}$} & & & \\
\hline & $\begin{array}{l}\text { na, } \\
\text { e surgery, } \\
\text { on }\end{array}$ & $\begin{array}{l}\text { utilized included: } 34 \text { primary closures, } 22 \text { gastrocnemius and soleus flaps, } 3 \text { bipe } \\
2 \text { sural artery flaps, } 1 \text { pedicled anterolateral thigh flap, } 3 \text { pedicled posterior th } \\
\text { subsequent above-knee amputations. No free flap based reconstructions were pe } \\
\text { algorithm for reconstruction of leg defects in the setting of limb-salvage surgery } \\
\text { Successful limb salvage rate was } 95.4 \% \text {. Limb salvage failed in } 3 \text { patients and t } \\
\text { amputation. Finally, } 56 \text { patients were able to ambulate without assistance at las } \\
\text { Conclusion: The authors present an algorithm for the reconstruction soft tissue af } \\
\text { of lower extremity bone sarcomas. The use of these techniques helps to decrease cc } \\
\text { and maximize function in children with these tumors. }\end{array}$ & $\begin{array}{l}\text { h flaps for } \\
\text { ormed. An } \\
\text { presented. } \\
\text { y required } \\
\text { follow-up. } \\
\text { r resection } \\
\text { iplications }\end{array}$ \\
\hline
\end{tabular}

\section{INTRODUCTION}

Primary bone cancers which include osteosarcoma (OS) and the Ewing sarcoma family of tumors (ESFT) represent approximately 2,400 cases or $0.2 \%$ of new cancers diagnosed in the United States each year. ${ }^{[1,2]}$ Malignant bone tumors account for $6 \%$ of neoplasms among children and $57 \%$ of those tumors occur in bones of the lower extremities. ${ }^{[3]}$

Limb sparing resections have evolved with advances in reconstructive surgery, orthopedic oncologic surgery, medical oncology, and radiation oncology..$^{[4-7]}$ Limbsparing surgery is now the treatment of choice for

(i) (5) This is an open access article distributed under the terms of the Creative Commons AttributionCC BY NC SA NonCommercial-ShareAlike 3.0 License, which allows others to remix, tweak, and build upon the work non-commercially, as long as the author is credited and the new creations are licensed under the identical terms.

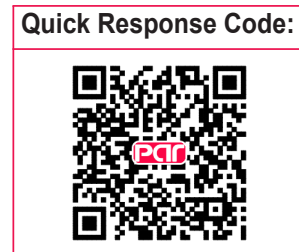


$90 \%$ of children. Limb-sparing resections provide the advantage of avoiding amputation but often results in a defect of bone and soft-tissue and function disability. Reconstruction of these defects and mitigating these functional disabilities is critical to achieving limb salvage..$^{[8]}$

Allografts, ${ }^{[9-12]}$ autografts, ${ }^{[13-16]}$ or endoprosthese ${ }^{[17-20]}$ are used to reconstruct bony defects depending on the type and circumstance with much debate in the literature. Soft tissue reconstruction is equally mired in controversy. Some authors describe primary closure, ${ }^{[21-24]}$ while others recommend local flaps ${ }^{[25-28]}$ or free flaps. ${ }^{[29-32]}$ Small patient cohorts, a variety of tumor types, and different treatment protocols, complicate data on this subject. ${ }^{[3-35]}$ The purpose of this study is to report clinical characteristics and management in the largest single-center series of lower extremity limb sparing surgeries after treatment for bone sarcomas in children and adolescents. An algorithm based on this extensive patient population is also presented.

\section{METHODS}

\section{Surgical technique}

At the time of the ablative procedure, tumors were resected to clear margins. Bony reconstruction was performed with a variety of techniques, including allografts and endoprostheses. The reconstruction of soft tissue varied from patient to patient and included primary closure, skin grafts, local and pedicled flaps. No free flaps were utilized in this series. For wound healing complications, various techniques were used. For superficial wound healing issues local debridement was performed either at bedside or under local. After debridement a wound vacuum-assisted closure (VAC) device was usually placed until the wound healed. For deep wound complications including dehiscence we returned to the operating room for debridements, implant revision/ replacement, re-closure, skin grafting, and/or flap reconstruction. ${ }^{[30-33]}$ The choice of flap reconstruction was made based on the orientation and type of wound as well as availability of donor tissue. Flap donor sites were either skin grafted or closed primarily. All patients underwent rehabilitation per our predefined protocols. ${ }^{[36,37]}$

\begin{abstract}
Patient
Our instit of this st children salvage $f$ center o to Decel at our $\mathrm{m}$

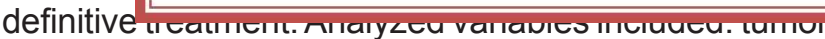
location; gender; age; tumor size; tumor pathology; last follow-up date; radiotherapy; age at diagnosis; chemotherapy; number and extent of resections; number and site of tumor recurrence(s); pathologic margins of disease; and perioperative and long-term complications. Recurrences were defined as lesions that were biopsy-proven recurrent tumors.
\end{abstract}

Adjuvant therapy was provided per any protocol under which the patient was enrolled at the time of treatment and as judged appropriate by the care team. External beam radiotherapy was the only technique used for radiation therapy, in the setting of ESFT, with median dose of $58.4 \mathrm{~Gy}$. Chemotherapy drugs most frequently included doxorubicin, cisplatin, methotrexate, and/or Bevacizumab.

Time to local failure and recurrence-free survival were calculated from the time of surgery performed at our institution to the first diagnosis of a local recurrence. Children who did not have a recurrence on or before their date of last contact or death were censored at this date.

\section{RESULTS}

\section{Patient and disease characteristics}

Eighty-two patients were evaluated for lower extremity bone sarcoma at SJCRH during the study period. Nine patients did not have any surgery, and 8 patients underwent primary amputation, leaving 65 patients included for analysis. With respect to upper leg/ thigh tumors, 9 patients had proximal femur tumors; 4 patients had mid-femur tumors; 24 had distal femur tumors; and 4 patients had tumors that involving the entire femur. With regard to leg tumors, 21 patients had proximal tibial tumors; 1 patient had a distal tibial tumor; and 2 patients had proximal fibula tumors. Patients with primary pelvic tumors were excluded from analysis. Patients with mid-shaft tibial tumors were classified either as proximal or distal tibial tumors, depending on the relative location of the primary tumor.

There were 65 primary limb-salvage surgeries. There were an additional 61 procedures during the perioperative/ adjuvant therapy timeframe; and 130 long-term procedures (including non-invasive expansions). Excluding non- 
Table 1: Patient and disease characteristics at baseline $(n=65)$

\begin{tabular}{ll}
\hline Patient characteristics & Median (range), or $\boldsymbol{n}$ (\%) \\
\hline Age at diagnosis, years & $13.0(2.9-23.3)$ \\
Gender, male/female & $36(55.4) / 29(44.6)$ \\
History of incisional biopsy & $65(100)$ \\
History of previous resection & $0(0)$ \\
Tumor pathology & \\
Osteosarcoma & $50(76.9)$ \\
Ewing sarcoma family of tumors & $15(23.1)$ \\
Tumor focality & \\
Localized & $51(78.4)$ \\
Regional & $2(3.1)$ \\
Metastatic & $12(18.5)$ \\
\hline
\end{tabular}

invasive expansions, the total number of procedures during the post-treatment period was 87 . Characteristics of the patient cohort are detailed in Table 1.

Patients at presentation had a median age of 13 years with a range of 2.9 to 23.3 years. Thirty-six were male and 29 were female. All patients had a history of an incisional biopsy of their primary tumor and any metastatic sites.
Table 2: Treatment characteristics $(n=65)$

\begin{tabular}{ll}
\hline Treatment characteristics & Median (range), or $\boldsymbol{n}$ (\%) \\
$\begin{array}{l}\text { Surgery } \\
\text { Intent of surgery }\end{array}$ & $65(100)$ \\
$\quad$ Curative & $65(100)$ \\
$\quad$ Debulking & $0(0)$ \\
Surgical margins & \\
R0 (microscopic negative) & $62(95.4)$ \\
R1 (microscopic positive) & $1(1.5)$ \\
R2 (macroscopic positive) & $2(3.1)$ \\
Defect volume, cm ${ }^{3}$ & $799(197-3,697)$ \\
Osteotomy length, cm & $23.7(8.5-71)$ \\
Bone reconstruction technique & \\
Modular endoprosthesis & $42(64.6)$ \\
Allograft & $7(10.8)$ \\
Expandable endoprosthesis & $12(18.5)$ \\
Bone transport rod & $3(4.6)$ \\
None & $1(1.5)$ \\
Soft tissue reconstruction technique & \\
Primary closure & $34(52.4)$ \\
Gastrocnemius/soleus muscle flap & $22(33.8)$ \\
Bipedicled flap & $3(4.6)$ \\
Sural artery flap & $2(3.1)$ \\
Pedicled anterolateral thigh flap & $1(1.5)$ \\
Pedicled posterior thigh flap & $3(4.6)$ \\
Free flap & $0(0)$
\end{tabular}

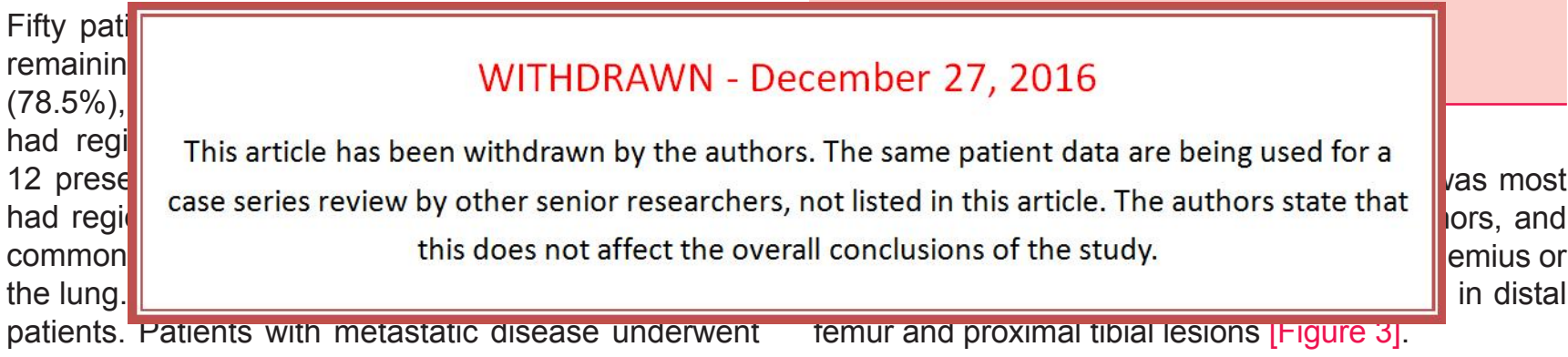
resection of the primary tumor, as well as any metastatic sites.

\section{Details of management}

A multidisciplinary solid tumor board met to discuss each case before the initiation of treatment. All children underwent a curative surgical resection $(n=65)$ [Table 2]. Only 1 child needed additional resection for local control of the primary tumor [this patient underwent above-knee amputations (AKA) secondary to local recurrence]. For patients presenting with metastatic disease, treatment included resection of the primary tumor, as well as any metastatic sites.

The median bone and soft tissue defect volume was $799 \mathrm{~cm}^{3}$ with a range of range 197 to $3,697 \mathrm{~cm}^{3}$. Osteotomy length had a median length of $23.7 \mathrm{~cm}$ with a range of 8.5 to $62.5 \mathrm{~cm}$. The longest specimen in the series was a total femur tumor, including resection from the femoral head to mid-tibia. At the time of the index procedure, soft tissue reconstruction was performed with primary closure in 45 patients. Gastrocnemius or soleus flaps with patellar tendon reconstruction
Pathological margin status was evaluated for all resections. Sixty-two cases had negative margins (R0); 1 patient had microscopic margins positive at the time of resection (R1); and 2 patients had macroscopic positive tumor margins at the time of resection (R2). The incidence of an R0 margin was not significantly different between patients who had local (48 of 51, $94.1 \%$ ), locoregional (2 of $2,100 \%$ ), or metastatic disease at the time of presentation (11 of 12, 91.7\%) ( $P=0.94$, Pearson's chi-squared test). Sixty-two of the 65 children received systemic chemotherapy at during their treatment. Fifty-six received preoperative chemotherapy, and 59 patients received postoperative chemotherapy. Five patients underwent for ESFT with a mean dose 58.4 Gy.

Bone reconstruction consisted of modular endoprosthesis in 42 patients; allograft in 7 patients; bone transport rod in 3 patients; expandible endoprosthesis (Repiphysis) in 12 patients; and 1 patients had no bone reconstruction (for fibula-only resection) [Figures 4 and 5]. Details of soft tissue reconstruction are discussed below. 


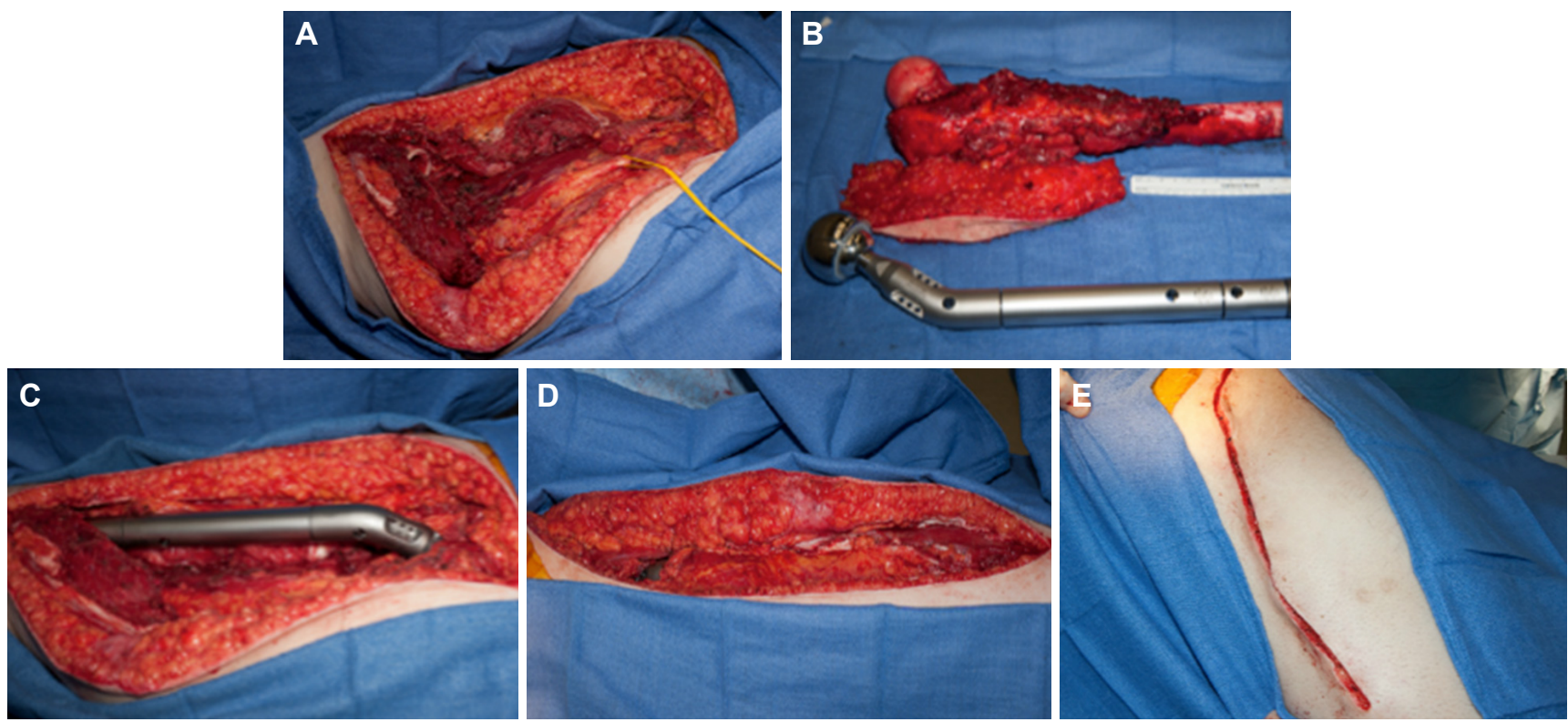

Figure 1: Proximal femoral resection and reconstruction with endoprosthesis. A: proximal femoral resection site; B: resection specimen and endoprosthesis; C: site after placement of endoprosthesis; D: soft tissue fascial and muscular closure over endoprosthesis; E: primary closure of soft tissue defect is possible, given anatomic orientation of soft tissue defect and reconstruction

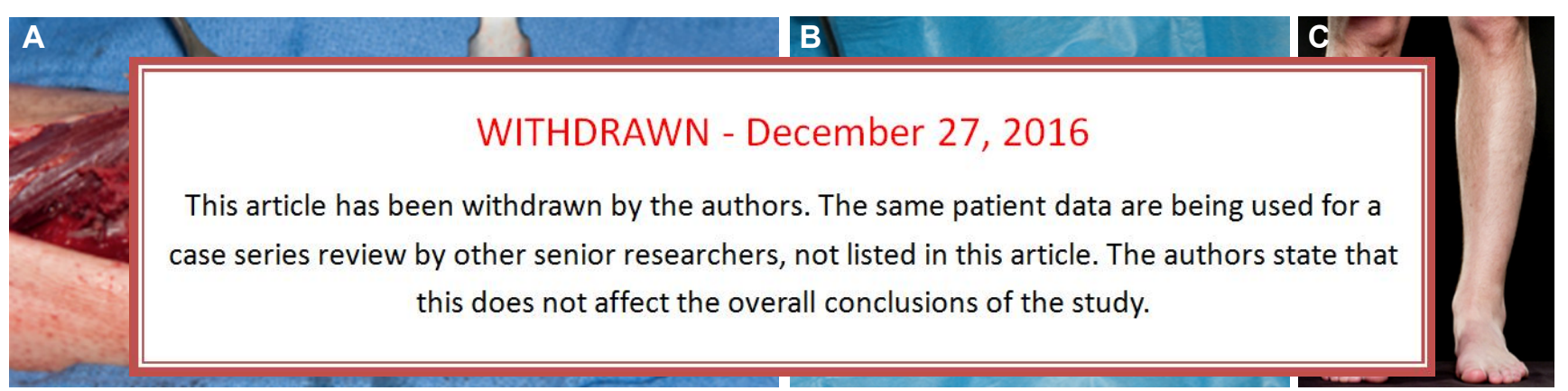

Figure 2: Bone and soft tissue reconstruction of distal tibia defect. A: bone reconstruction is performed with Phenix ${ }^{\mathrm{TM}}$ bone transport rod; B: endoprosthesis is covered in muscular and soft tissue envelope, and skin is closed with primary closure; C: photo at 3-month follow-up

\section{Management of complications during cancer treatment}

We divided complications into three major categories based on how they were temporally related to surgery. The initial post operative period of 30 days, followed by the period they were undergoing adjuvant therapy and finally after the completion of their therapy. Then they were further subdivided into patients with soft-tissue, implant and long term functional complications.

Eighteen of 65 patients had an initial 30-day postoperative complication. Four patients had cellulitis treated with oral or intravenous antibiotics; 5 patients had a nonoperative wound complication; 7 patients had a deep wound dehiscence requiring operative debridement; and 3 suffered a popliteal artery thrombosis, 1 of these had a successful thombectomy, 2 resulted in AKA (1 patient had multiple complications). No patients had bone or implant related complications during the 30 -day perioperative period. All patients were able to successfully resume planned adjuvant therapy postoperatively despite any immediate complications. A single patient had a protocol alteration due to surgical pathology, which found a low-grade OS and did not require further adjuvant therapy as planned.

Twenty-eight patients did not have any complications during their treatment period. Sixteen patients had a nonoperative minor wound complication (e.g. cellulitis, superficial wound dehiscence/ eschar). Twenty-nine patients had an operative complication, requiring a total of 52 procedures. Of these 52 procedures, $38(73.1 \%)$ were soft tissue complications requiring surgery; 14 $(26.9 \%)$ were bone/implant-related complications. There were an additional 11 metastatectomies (not counted as complications). Of 29 patients requiring surgery during the adjuvant therapy period, adjuvant therapy was delayed in 26; 2 patients did not delay therapy; and 1 patient did not require adjuvant therapy since the limb was amputated secondary to vascular 

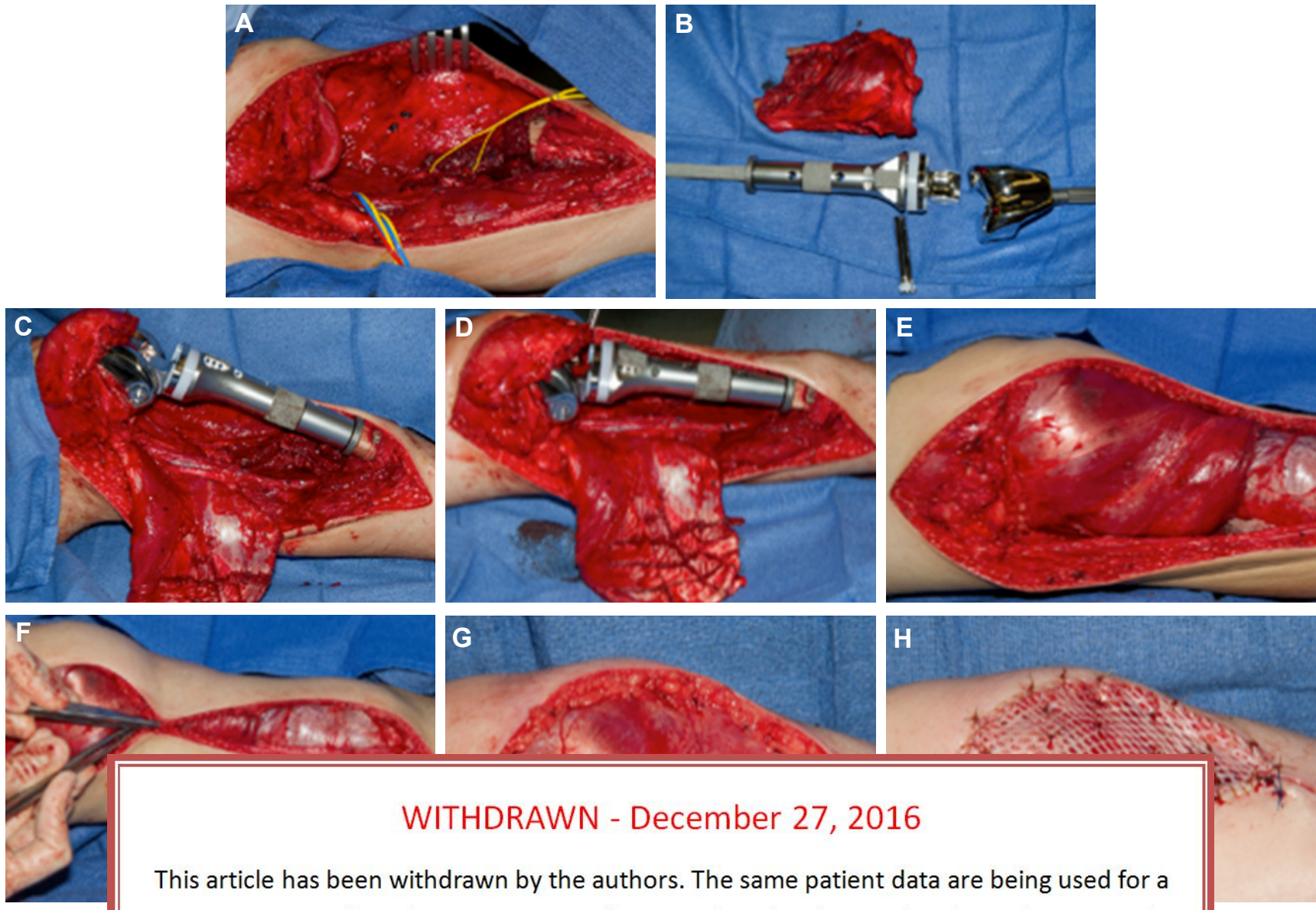

Figure 3: B: tumor s with gastrc and skin g
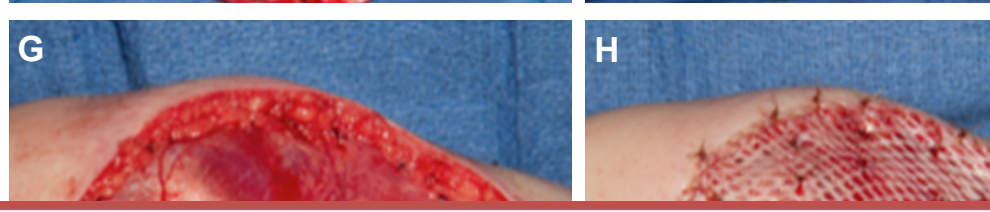

\section{WITHDRAWN - December 27, 2016}

This article has been withdrawn by the authors. The same patient data are being used for a case series review by other senior researchers, not listed in this article. The authors state that this does not affect the overall conclusions of the study.
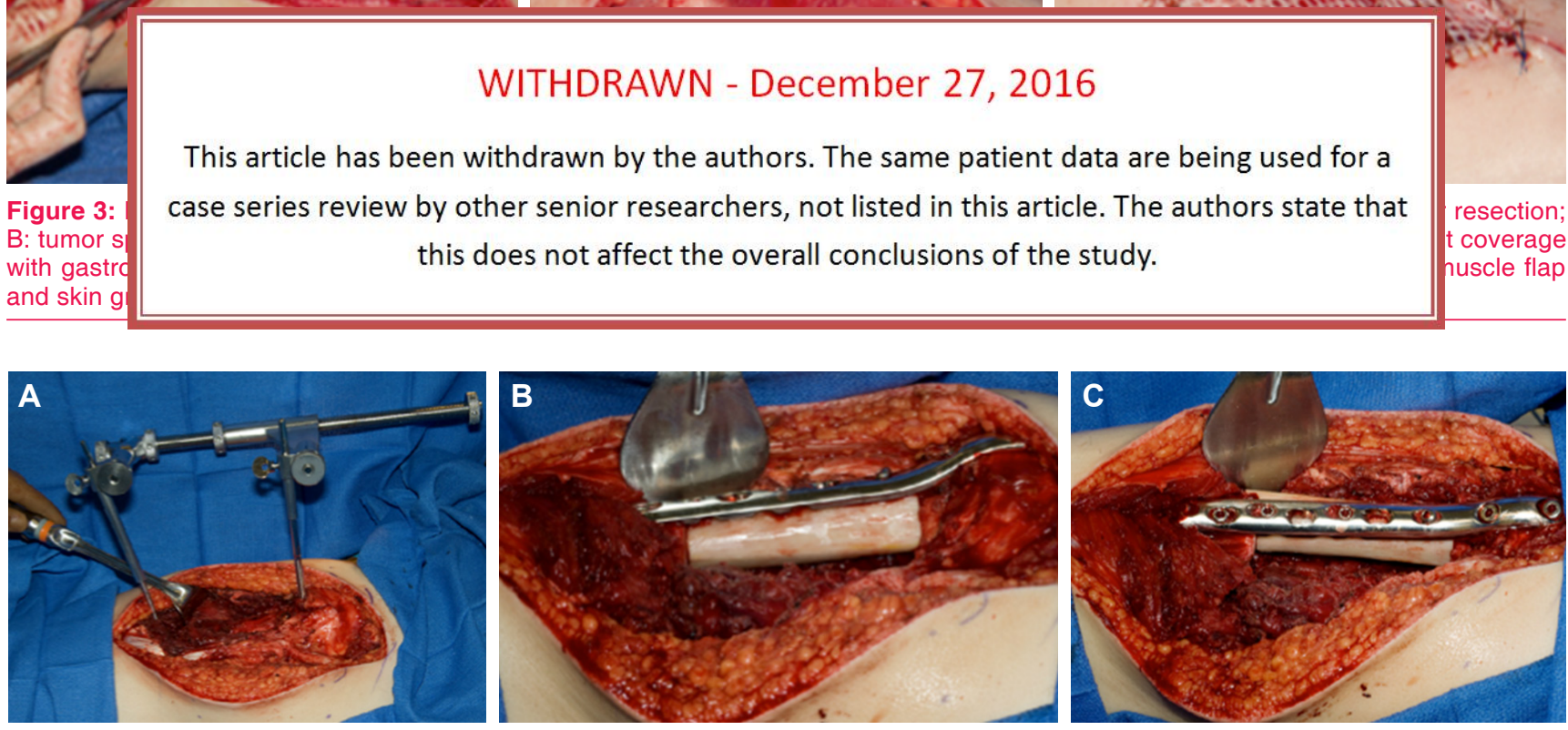

Figure 4: Mid-femur bone replacement with allograft. A: proximal and distal bone segments are held in place with steinman pins and skeletal traction; B and C: bone allograft is placed in segmental femoral defect, and held in place with spanning plate (lateral and oblique views, respectively)

injury. During the combined 30-day postoperative and adjuvant therapy treatment periods, soft tissue closure was achieved with primary closure in 37 cases. Two cases required bipedicled lower leg flap; 1 case required sural artery flap; 1 pedicled anterolateral thigh (ALT) flap; 2 pedicled gastrocnemius flaps; 2 pedicled posterior thigh flaps (for amputations); and split thickness skin graft was utilized in 3 cases. No patients required free flap closure.

\section{Recurrence and overall survival}

Median follow-up was 37 months with a range of 6 months to 6.8 years. After conclusion of the study, 22 of the 65 patients did not have any further surgical complications. The 43 remaining patients had a total of 130 procedures during the post-adjuvant therapy period. Endoprosthesis expansions were performed utilizing a non-invasive Repiphysis device, and were not counted 

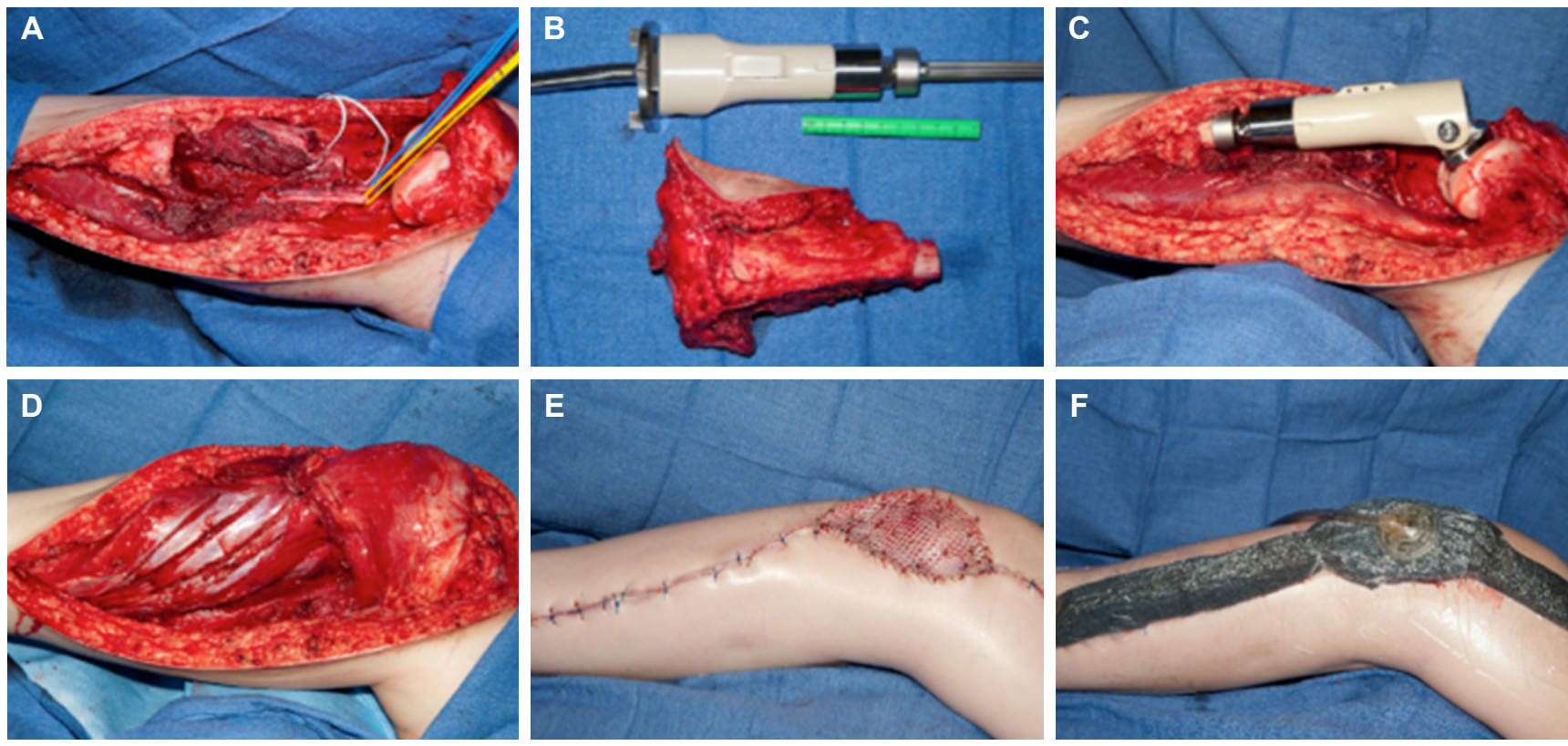

Figure 5: Proximal tibia osteosarcoma reconstructed with Repiphysis expandable endoprosthesis and muscle flap coverage. A: surgical defect and en bloc tumor resection; B: tumor specimen and Repiphysis endoprosthesis in situ; C: placement of Repiphysis implant; D, $\mathrm{E}$, and $\mathrm{F}$ : soft tissue reconstruction with muscle flaps, proximal and distal primary closure, skin grafting and incisional wound vacuumassisted closure

\begin{tabular}{|c|c|c|}
\hline \multirow{2}{*}{$\begin{array}{l}\text { as additic } \\
\text { were for } \\
\text { operative } \\
\text { related } \\
\text { above); } \\
1 \text { AKA s } \\
1 \text { neuron } \\
\text { after AKA }\end{array}$} & \multirow{2}{*}{\multicolumn{2}{|c|}{$\begin{array}{r}\text { This article has been withdrawn by the autho } \\
\text { case series review by other senior researchers } \\
\text { this does not affect the ove }\end{array}$}} \\
\hline & & \\
\hline \multicolumn{2}{|c|}{ Table 3: Long term outcomes $(n=65)$} & $\begin{array}{l}\text { ssue closure, } 1 \text { posterio } \\
n=65)\end{array}$ \\
\hline Outcome & & Median (range), or $n(\%)$ \\
\hline \multicolumn{3}{|c|}{ Ambulatory status } \\
\hline Independ & ent ambulation & $56(86.1)$ \\
\hline Ambulate & with assist device & $7(10.8)$ \\
\hline Non-ambi & ulatory & $2(3.1)$ \\
\hline \multicolumn{3}{|l|}{ Follow-up } \\
\hline Disease-f & ree survival, years & $3.1(0.5-6.8)$ \\
\hline Time to re & currence, months & $13(2-46)$ \\
\hline \multicolumn{3}{|c|}{ Disease status at last follow-up } \\
\hline No eviden & ce of disease & $43(66.2)$ \\
\hline Stable dis & ease & $9(13.8)$ \\
\hline Progressi & ve disease & $4(6.2)$ \\
\hline Died from & disease & $6(9.2)$ \\
\hline Lost to fol & llow-up & $3(4.6)$ \\
\hline \multicolumn{3}{|c|}{ Therapy status at last follow-up } \\
\hline Complete & d therapy & $54^{*}(83.1)$ \\
\hline On therap & & $8(12.3)$ \\
\hline Failed the & rapy & $3(4.6)$ \\
\hline \multicolumn{3}{|l|}{ Limb status } \\
\hline Salvaged & & $62(95.4)$ \\
\hline Amputatic & & $3(4.6)$ \\
\hline Implant m & lalfunctions & $26(40)$ \\
\hline
\end{tabular}

*One patient did not require any adjuvant therapy. y closure 3 reports patients,

lated 54 ncologic

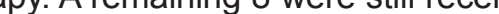
an addition three failed to complete their full course. At the most recent follow-up available, 43 had no evidence of any disease; 9 patients had stable disease; 4 patients had progressive disease; 6 patients had died of their disease; and 3 patients had been lost to follow up. With regard to recurrences, there was one local recurrence (as described above); one locoregional recurrence; 6 lung metastases; 3 spinal metastases; and 1 each of kidney, chest wall, and skull metastases. The median time to a recurrence was 13 months with a range of 2 months to 3.8 years. At the time of last available follow-up, 3 patients had had amputations; 56 patients were able to ambulate without any assistance; 7 patients required an assist device (e.g. brace, ankle foot orthosis, crutch, prosthesis); and 2 patients were completely non-ambulatory.

\section{DISCUSSION}

Limb-sparing surgery is now the standard of care for primary bone tumors, especially in the pediatric population. ${ }^{[3,4,6,7]}$ Wide en bloc resection of bone and soft tissue is needed to avoid local recurrence and 


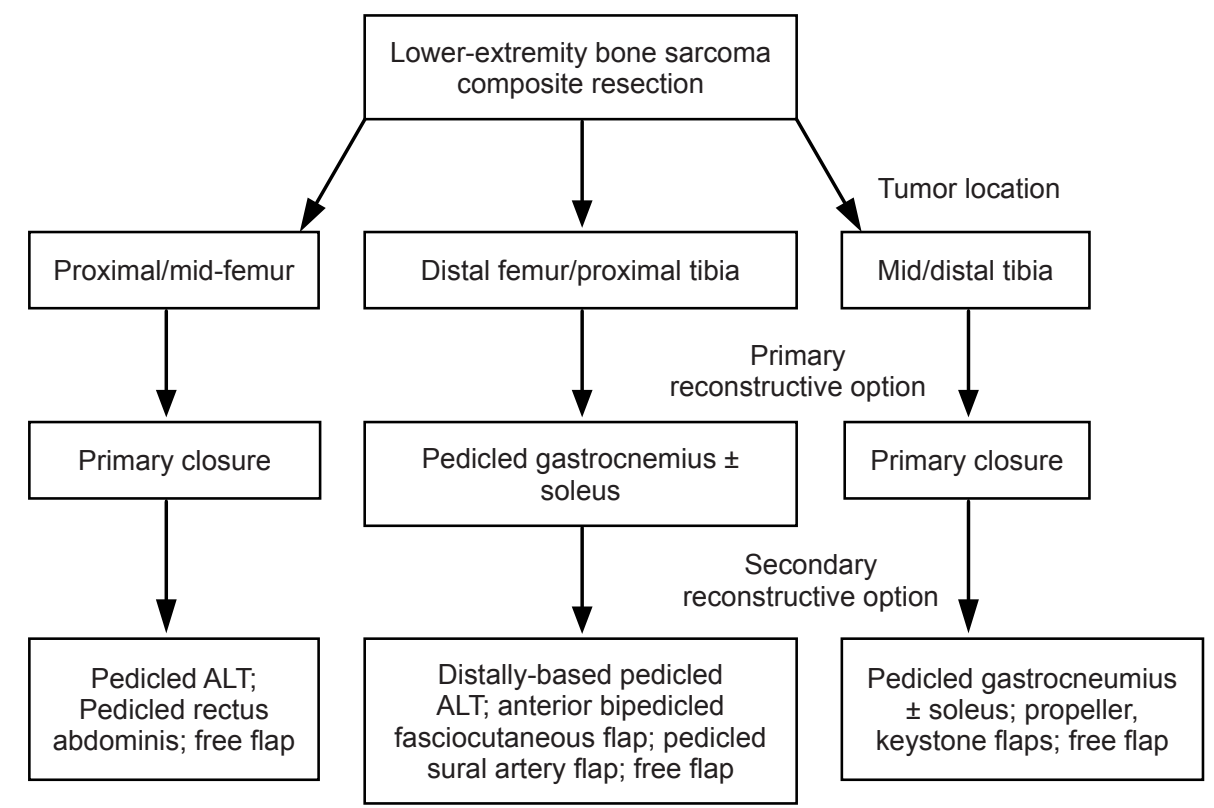

Figure 6: Algorithm for lower extremity reconstruction after composite resection for bone sarcoma. Defects of the proximal and midfemur were successfully closed with primary closure in the majority of cases; backup options included pedicled ALT, and rectus abdominis flaps, and free flaps. Defects of the distal femur and proximal tibia were successfully closed with pedicled gastrocnemius flaps, often with inclusion of the soleus muscle. Backup options include distally-based pedicled ALT flaps, anterior bipedicled fasciocutaneous flaps, pedicled sural artery flaps, and free flaps. Defects of the mid- to distal tibia were successfully closed with primary closure in the majority of cases. Backun ontions include nedicled aastrocnemius and soleus flans oroneller or kevstone flans. and free flans. Al T: anterolateral thigh -

long term in large large fur This pap soft tissu of patien

This article has been withdrawn by the authors. The same patient data are being used for a case series review by other senior researchers, not listed in this article. The authors state that this does not affect the overall conclusions of the study. of deep nanaged bedside C. More y treated iccessful
Three patients who underwent hinged knee endoprostheses suffered popliteal artery thrombosis, which resulted in 2 AKA's. These cases were reviewed and are thought to be most likely due to a traction injury that occurred during implant placement. This phenomenon has been described ${ }^{[39]}$ in the literature and we now place these implants with direct visualization of the neurovascular bundle. In addition care is taken to prevent excess traction on the lower leg, with judicious use of a tourniquet. Vascular exams are also performed preoperatively, intraoperatively, and postoperatively. Aside from these events, perioperative complications were acceptable with only 10 of 65 patients requiring operative intervention. Most wound complications could be managed with a bedside debridement and negative pressure wound therapy.

Wound complications were common during the period when patients received adjuvant therapy. Our institutional protocols for these tumors feature early, aggressive multi-agent adjuvant chemotherapy. Experience during this treatment period has been especially instructive. Wound complications that were
IIImo salvage rate. For wounas arouna tne knee and anterior incision, we elevated a bipedicled anterior leg fasciocutaneous flap. We transposed this to the defect and then skin grafted the donor site. This fasciocutaneous tissue was widely undermined during the index procedure and so it is a delayed flap and tolerates mobilization well. If a patient had a wound along the posterior portion of a knee incision, we elevated a sural artery fasciocutaneous flap. We found this procedure successful, as the large sural artery perforators are not generally injured during the initial reconstruction. Additional options include distallybased ALT flaps and free flaps. Femoral defects could typically be closed primarily since bone sarcoma resections in this region usually spared the majority of the soft tissue. In rare cases where soft tissue was required, defects were closed with proximally- and distally-based ALT flaps. Other options include pedicled rectus flaps and free flaps. While it is often taught that mid- to distal-tibial lesions require free tissue transfer for wound coverage, we found that these soft tissue defects were often small and frequently amenable to primary closure. For recurrent or complicated wounds, gastrocnemius and freestyle propeller-type flaps were 
adequate in our study. Other options include keystone flaps, pedicled flaps from the distal leg and foot, and free flaps ${ }^{[35,40]}$ An algorithm outlining our approach to soft tissue coverage is shown in Figure 6.

One novel finding of our study pertains the timing of complication types, and need for reoperation. We observed that early complications were usually soft tissue related, whereas late complications were usually related to bone reconstruction. Specifically, in the 30-day postoperative period, 10 of 10 operative complications were soft-tissue related; in the adjuvant therapy period, 38 of 52 were soft tissue related, and 11 of 52 were implant related; and in the post-adjuvant period, 14 of 130 were soft tissue related, while 51 of 130 were implant related (chi-square test, $P<0.001$ ). Based on these findings, we propose 2 primary softtissue reconstructive goals: facilitation of adjuvant therapy, and the ability to re-operate for late implantrelated issues.

In many patients, we use unique implants that obviate multiple operating room trips for expansion, including Repiphysis which is an exnandable endonrosthesis in addition $\operatorname{rod}_{.}[26-28]$ expensiv the need invasive these de

This article has been withdrawn by the authors. The same patient data are being used for a case series review by other senior researchers, not listed in this article. The authors state that this does not affect the overall conclusions of the study.

The maj

infection or hardware exposure. There was only one patient who had a late limb loss secondary to local recurrence. Nearly all attained excellent functional results including ambulation with full active and passive range of motion of the ankle, hip and knee joints.

From the perspective of their oncologic treatment outcomes were superb with a single local recurrence. Six patients died secondary to metastatic disease. This mortality rate (i.e. $9 \%$ ) is low relative to established 10-year follow-up mortality rates for OS and ESFT, and may be a consequence of our short follow-up (3.1 years). Overall, $62(95.4 \%)$ of limbs were successfully salvaged, with $43(66.2 \%)$ of patients free of disease at last follow-up. Although invaluable for limb salvage surgery, microsurgical reconstruction was not utilized in any of these pediatric cases. The most likely reason for this is an institutional bias towards minimizing the magnitude of the surgery in this young (i.e. pediatric) demographic. While our long-term results are excellent using the algorithm described, the authors recognize that many of our patients would likely benefit from microsurgical techniques. Patients who are known to need frequent implant revisions could benefit from a

\section{REFERENCES} 1975;57:268-9. bone tumors. Johns Hopkins Med J 1977;140:85-96. vascularized fibula flaps. Plast Reconstr Surg 2012;129:195-206.

4. Mastorakos DP, Disa JJ, Athanasian E, Boland P, Healey JH, Cordeiro fibula osteoseptocutaneous flap. Microsurgery 2002;22:193-8.

6. Harrison DH. The osteocutaneous free fibular graft. J Bone Joint Surg Br 1986;68:804-7. and limitations. Ital J Orthop Traumatol 1986;12:447-54.

8. Chen CM, Disa JJ, Lee HY, Mehrara BJ, Hu QY, Nathan S, Boland

9. Germain MA, Dubousset J, Mascard E, Kalifa C. [Vascularized more robust flap skin paddle that would better tolerate multiple reoperations. Futures studies identifying and evaluating those at risk could prove useful.

In conclusion, lower extremity limb sparing surgery is difficult, demanding extensive bone, tendon, and soft tissue reconstruction. We have found a number of techniques for soft tissue reconstruction that ultimately result in successful limb salvage in nearly all patients. Early complications are usually soft tissue related, and late complications are usually related to bone reconstruction. Thus, operative goals should provide for soft tissue reconstructive options that allow for immediate continuation of adjuvant therapy, the potential for long-term implant revision, and the optimization of oncologic safety and soft tissue integrity. Together, these options provide dependable bony and soft tissue reconstruction essential for successful limb salvage surgery.

\section{Financial support and sponsorship} None.

\section{Conflicts of interest}

1. Sweetnam R. Amputation in osteosarcoma. J Bone Joint Surg Br

2. Weiland AJ, Daniel RK, Riley LH Jr. Application of the free vascularized bone graft in the treatment of malignant or aggressive

3. Schwarz GS, Disa JJ, Mehrara BJ, Healey JH, Cordeiro PG. Reconstruction of oncologic tibial defects in children using PG. Soft-tissue flap coverage maximizes limb salvage after allograft bone extremity reconstruction. Plast Reconstr Surg 2002;109:1567-73.

5. El-Gammal TA, El-Sayed A, Kotb MM. Microsurgical reconstruction of lower limb bone defects following tumor resection using vascularized

7. Croce F, Risorto M, Coviello M, Di Maggio B, Galluzzi V, Monteleone P. Vascularised fibula transplant. Technique, early results, indications P, Healey J, Cordeiro PG. Reconstruction of extremity long bone defects after sarcoma resection with vascularized fibula flaps: a 10year review. Plast Reconstr Surg 2007;119:915-24; discussion 925-6. 
peroneal reconstruction after bloc resection of tumors or congenital malformations of the upper limb in children]. Bull Acad Natl Med 2000;184:1671-84; discussion 1685-6. (in French)

10. Lee SH, Kim HS, Park YB, Rhie TY, Lee HK. Prosthetic reconstruction for tumours of the distal tibia and fibula. J Bone Joint Surg $\mathrm{Br}$ 1999;81:803-7.

11. Donati D, Di Liddo M, Zavatta M, Manfrini M, Bacci G, Picci P, Capanna R, Mercuri M. Massive bone allograft reconstruction in highgrade osteosarcoma. Clin Orthop Relat Res 2000;(377):186-94.

12. Ozaki T, Hillmann A, Wuisman P, Winkelmann W. Reconstruction of tibia by ipsilateral vascularized fibula and allograft. 12 cases with malignant bone tumors. Acta Orthop Scand 1997;68:298-301.

13. Hornicek FJ, Gebhardt MC, Tomford WW, Sorger JI, Zavatta M, Menzner JP, Mankin HJ. Factors affecting nonunion of the allografthost junction. Clin Orthop Relat Res 2001;(382):87-98.

14. Helmstedter CS, Goebel M, Zlotecki R, Scarborough MT. Pathologic fractures after surgery and radiation for soft tissue tumors. Clin Orthop Relat Res 2001;(389):165-72.

15. Heller L, Kronowitz SJ. Lower extremity reconstruction. J Surg Oncol 2006;94:479-89.

16. Amr SM, El-Mofty AO, Amin SN, Morsy AM, El-Malt OM, AbdelAal HA. Reconstruction after resection of tumors around the knee: role of the free vascularized fibular graft. Microsurgery 2000;20:233-51.

17. Malizos KN, Nunley JA, Goldner RD, Urbaniak JR, Harrelson JM. Free vascularized fibula in traumatic long bone defects and in limb salvaging following tumor resection: comparative study. Microsurgery 1993;14:368-74. of segmental defects of the radius with use of the vascularized osteoseptocutaneous fibular autogenous graft. J Bone Joint Surg Am 1997;79:542-50

26. Neel MD, Wilkins RM, Rao BN, Kelly CM. Early multicenter experience with a noninvasive expandable prosthesis. Clin Orthop Relat Res 2003;415:72-81.

27. Gitelis S, Neel MD, Wilkins RM, Rao BN, Kelly CM, Yao TK. The use of a closed expandable prosthesis for pediatric sarcomas. Chir Organi Mov 2003;88:327-33.

28. Konofaos P, Kashyap A, Neel MD, Ver Halen JP. A novel device for long bone osteodistraction: description of device and case series. Plast Reconstr Surg 2012;130:e418-22.

29. Patel RM, Cavo M, Patel A, Albarillo M, Puri L. Wound complications in joint arthroplasty: comparing traditional and modern methods of skin closure. Orthopedics 2012;35:641-6.

30. Lian G, Cracchiolo A 3rd, Lesavoy M. Treatment of major wound necrosis following total knee arthroplasty. J Arthroplasty 1989;4 Suppl:S23-32.

31. Gill NA, Hameed A. The sural compendium: reconstruction of complex soft-tissue defects of leg and foot by utilizing the posterior calf tissue. Ann Plast Surg 2012;69:203-8.

32. Suri MP, Friji MT, Ahmad QG, Yadav PS. Utility of proximally based sural artery flap for lower thigh and knee defects. Ann Plast Surg 2010;64:462-5.

33. Ver Halen JP, Soto-Miranda MA, Hammond S, Konofaos P, Neel M, Rao B. Lower extremity reconstruction after limb-sparing sarcoma resection of the proximal tibia in the pediatric population: case series

18. Heit of the Joint S

WITHDRAWN - December 27, 2016

19. Moran with in This article has been withdrawn by the authors. The same patient data are being used for a adoles case series review by other senior researchers, not listed in this article. The authors state that

20. Hiern vascul bone this does not affect the overall conclusions of the study. 1995; 1

21. Jones NF, Swartz WM, Mears DC, Jupiter JB, Grossman A. The "double barrel" free vascularized fibular bone graft. Plast Reconstr Surg 1988;81:378-85.

22. Mankin HJ, Doppelt SH, Sullivan TR, Tomford WW. Osteoarticular and intercalary allograft transplantation in the management of malignant tumors of bone. Cancer 1982;50:613-30.

23. Capanna R, Campanacci DA, Belot N, Beltrami G, Manfrini M, Innocenti M, Ceruso M. A new reconstructive technique for intercalary defects of long bones: the association of massive allograft with vascularized fibular autograft. Long-term results and comparison with alternative techniques. Orthop Clin North Am 2007;38:51-60, vi.

24. Ceruso M, Falcone C, Innocenti M, Delcroix L, Capanna R, Manfrini M. Skeletal reconstruction with a free vascularized fibula graft associated to bone allograft after resection of malignant bone tumor of limbs. Handchir Mikrochir Plast Chir 2001;33:277-82.

25. Jupiter JB, Gerhard HJ, Guerrero J, Nunley JA, Levin LS. Treatment
2007;49:964-9.

37. Marchese VG, Rai SN, Carlson CA, Hinds PS, Spearing EM, Zhang L, Callaway L, Neel MD, Rao BN, Ginsberg JP. Assessing functional mobility in survivors of lower-extremity sarcoma: reliability and validity of a new assessment tool. Pediatr Blood Cancer 2007;49:183-9.

38. Busfield BT, Huffman GR, Nahai F, Hoffman W, Ries MD. Extended medial gastrocnemius rotational flap for treatment of chronic knee extensor mechanism deficiency in patients with and without total knee arthroplasty. Clin Orthop Relat Res 2004;428:190-7.

39. Calligaro KD, Dougherty MJ, Ryan S, Booth RE. Acute arterial complications associated with total hip and knee arthroplasty. J Vasc Surg 2003;38:1170-5.

40. Demirseren ME, Efendioglu K, Demiralp CO, Kilicarslan K, Akkaya H. Clinical experience with a reverse-flow anterolateral thigh perforator flap for the reconstruction of soft-tissue defects of the knee and proximal lower leg. J Plast Reconstr Aesthet Surg 2011;64:1613-20. 